medRxiv preprint doi: https://doi.org/10.1101/2021.02.11.21251581; this version posted February 12, 2021. The copyright holder for this preprint

(which was not certified by peer review) is the author/funder, who has granted medRxiv a license to display the preprint in perpetuity.

This article is a US Government work. It is not subject to copyright under 17 USC 105 and is also made available for use under a CCO license.

\title{
A genetically-informed study disentangling the relationships between tobacco smoking, cannabis use, alcohol consumption, substance use disorders and respiratory infections, including COVID-19
}

Daniel B. Rosoff ${ }^{1,2^{*}}$, Joyce Yoo $^{1 *}$, Falk W. Lohoff ${ }^{1 \#}$.

${ }^{1}$ Section on Clinical Genomics and Experimental Therapeutics, National Institute on Alcohol Abuse and Alcoholism, National Institutes of Health, Bethesda, MD, USA

${ }^{2}$ NIH-Oxford-Cambridge Scholars Program; Nuffield Department of Population Health, University of Oxford, UK

*Authors contributed equally

${ }^{\#}$ Corresponding Author:

Falk W. Lohoff, M.D.

Chief, Section on Clinical Genomics and Experimental Therapeutics (CGET)

Lasker Clinical Research Scholar

National Institute on Alcohol Abuse and Alcoholism (NIAAA)

National Institutes of Health

10 Center Drive (10CRC/2-2352)

Bethesda, MD 20892-1540

Office: 301-827-1542

falk.lohoff@nih.gov 


\begin{abstract}
Background Observational studies suggest smoking, cannabis use, alcohol consumption, cannabis use, and substance use disorders (SUDs) may play a role in the susceptibility for respiratory infections and disease, including coronavirus 2019 (COVID-2019). However, causal inference is challenging due to comorbid substance use.
\end{abstract}

Methods Using genome-wide association study data of European ancestry (data from >1.7 million individuals), we performed single-variable and multivariable Mendelian randomization to evaluate relationships between smoking, cannabis use, alcohol consumption, SUDs, and respiratory infections.

Results Genetically predicted lifetime smoking was found to be associated with increased risk for hospitalized COVID-19 (odds ratio $(\mathrm{OR})=4.039,95 \%$ CI 2.335-6.985, $P$-value $=5.93 \times 10^{-7}$ ) and very severe hospitalized COVID-19 (OR=3.091, 95\% CI, 1.883-5.092, $P$-value $\left.=8.40 \times 10^{-6}\right)$. Genetically predicted lifetime smoking was also associated with increased risk pneumoniae $\left(\mathrm{OR}=1.589,95 \% \mathrm{CI}, 1.214-2.078, P\right.$-value $\left.=7.33 \times 10^{-4}\right)$, lower respiratory infections $(\mathrm{OR}=2.303$, $95 \%$ CI, $1.713-3.097, P$-value $\left.=3.40 \times 10^{-8}\right)$, and several others. Genetically predicted cannabis use disorder (CUD) was associated with increased bronchitis risk (OR=1.078, 95\% CI, 1.020$1.128, P$-value $=0.007)$.

\title{
Conclusions
}

We provide strong genetic evidence showing smoking increases the risk for respiratory infections and diseases even after accounting for other substance use and abuse. Additionally, we provide find CUD may increase the risk for bronchitis, which taken together, may guide future research SUDs and respiratory outcomes. 


\section{INTRODUCTION}

Since the first reported cases in Wuhan, China in December 2019, ${ }^{1}$ coronavirus disease 2019 (COVID-19) has subsequently affected more than 200 countries and continues to be a global pandemic of substantial worldwide morbidity and mortality. ${ }^{2,3}$ More broadly, upper and lower respiratory infections (URIs and LRIs, respectively), and other respiratory diseases (i.e., asthma, chronic obstructive pulmonary disease (COPD), etc.) are leading causes of yearly worldwide morbidity and mortality. ${ }^{4,5}$ For example, the Global Burden of Disease Study estimated that LRIs caused more than two million deaths globally in $2016,{ }^{4}$ while approximately 2.3 million people died from COPD in $2015 .^{5}$ Respiratory infection and diseases are also a large economic burden: URIs result in more than 40 million missed days of school and work per year. ${ }^{6}$

Substance use (tobacco smoking, cannabis use, and alcohol consumption) are risk factors linked with adverse lung and respiratory outcomes. ${ }^{7-9}$ For example, observational data has shown chronic heavy alcohol consumption to be associated with increased risk for pneumonia ${ }^{7}$ and acute respiratory distress syndrome, ${ }^{10}$ while cannabis smoke has been shown to contain many of the same toxins and irritants as smoke derived from tobacco, ${ }^{11}$ but may differ than tobacco in its association with bronchitis and other respiratory infections. ${ }^{12}$ In addition, it has been suggested that chronic alcohol abuse may compromise the ability of immune cells to destroy bacteria in the lungs, which may result in an increased vulnerability to respiratory infections like pneumonia and tuberculosis. ${ }^{13}$

Paralleling the COVID-19 pandemic have been increases in substance use, ${ }^{14}$ which combined with data showing approximately $10.8 \%$ of US adults have a substance use disorder (SUD) ${ }^{15}$ and recent work using electronic health records (EHRs) to show that individuals with a SUD are at increased risk for COVID-19 ${ }^{16}$ suggest identifying potential causal relationships between substance use, SUD and respiratory infectious disease would have substantial public health benefit.

However, observational studies cannot be used to reliably identify causality due to limitations such as residual confounding, and reverse causality. ${ }^{17}$ For example, outcomes reached from observational studies may be subject to unmeasured confounders like comorbid disorders or underlying genetic differences that may lead to biased estimates, and consequently, may not reflect true causal relationships. ${ }^{18,19}$ While, randomized controlled trials (RCTs) are considered the "gold standard", RCTs can be both unethical and impractical:"20,21 Constructing an RCT to examine the effect of substance use on respiratory infection risk may be complicated by other existing comorbidities.

Mendelian randomization (MR) is a genetic approach that uses genetic variants as instrumental variables to explore causal relations between exposures (e.g. alcohol consumption, tobacco smoking, cannabis use) and health outcomes (e.g. respiratory infections and diseases). This technique takes publicly available genome wide association studies to screen for suitable genetic instrumental variables, which allows researchers to perform MR studies without the need to recruit new patients. ${ }^{22}$ Because germline variants are randomly assorted at meiosis, MR may be 
medRxiv preprint doi: https://doi.org/10.1101/2021.02.11.21251581; this version posted February 12, 2021. The copyright holder for this preprint

(which was not certified by peer review) is the author/funder, who has granted medRxiv a license to display the preprint in perpetuity.

This article is a US Government work. It is not subject to copyright under 17 USC 105 and is also made available for use under a CCO license.

considered conceptually equivalent to RCTs, though a more naturalized version. ${ }^{19,22}$ More specifically, given genetic instruments cannot be influenced by other confounders (i.e., lifestyle, or environmental factors), MR studies, are in theory, less susceptible to confounding or reverse causality than traditional observational studies. ${ }^{23}$ Therefore, MR are an important analytical approach to strengthen causal inference when RCTs are challenging due to methodological or ethical constraints. ${ }^{24}$

Given the potential for confounding and limited causal inference derived from observational data, we used large, publicly available genome-wide association study (GWAS) data and twosample MR methods to evaluate the relationships between substance use, substance use disorders (CUD and alcohol use disorder (AUD)) and respiratory infection and disease outcomes.

\section{METHODS}

Data sources and genetic instruments. Summary-level data for both modifiable risk factor instrument and infectious disease outcome data were derived from publicly available GWASs in populations of predominantly European ancestry (Figure 1; Table 1 in the Supplement). All GWASs have existing ethical permissions from their respective institutional review boards and include participant informed consent and included rigorous quality control.

Tobacco smoking. We included lifetime smoking instruments from the recent GWAS of a lifetime smoking index (which combined smoking initiation, duration, heaviness and cessation), conducted in a sample of 462690 current, former and never smokers in the UKB (mean sore value 0.359 (S.D. = 0.694); sample, 54 percent female, mean age 56.7 years, 54 percent never smokers, 36 percent former smokers, and 11 percent current smokers). ${ }^{25}$ (An SD increase in lifetime smoking index score would be equivalent to smoking 20 cigarettes per day for 15 years and stopping 17 years previously or 60 cigarettes per day for 13 years and stopping 22 years previously). ${ }^{25}$ For this study, we included all SNPs associated at GWS $P<5 \times 10^{-8}$ and clumped at $\mathrm{LD} r^{2}=.001$ and a distance of $10000 \mathrm{~kb}$ (Table 2 in the Supplement).

Cannabis use. We included two cannabis-related instrument sets: cannabis use and CUD. Summary statistics for lifetime cannabis use (a yes/no variable of whether participants reported using cannabis during their lifetime) were obtained from the PGC meta-analysis GWAS of 3 cohorts (International Cannabis Consortium (35 297 respondents, 55.5 percent female, ages 1687, mean 35.7 years; 42.8 percent had used cannabis); UKB (126 785 respondents, 56.3 percent female, aged 39-72, mean age 55.0 years, 22.3 percent had used cannabis), and 23andMe (22 683 respondents, 55.3 percent female, ages 18-94, mean 54.0 years; 43.2 percent had used cannabis)). ${ }^{26}$ CUD instruments were obtained from a recent PGC meta-analysis of 3 cohorts of predominantly European ancestry (PGC, Lundbeck Foundation Initiative for Integrative Psychiatric Research (iPSYCH), and deCODE, excluding related individuals from PGC familybased cohorts; demographics not available), including 14808 cases of cannabis abuse or dependence defined as meeting DSM-IIIR, DSM-IV, DSM-5, or ICD10 codes (depending on study cohort) criteria; the 358534 controls were defined as anyone not meeting the criteria. ${ }^{27}$ To ensure independence, we included all SNPs associated with cannabis use at GWS $P<5 \times 10^{-8}$ and all SNPs association with CUD at $P<5 \times 10^{-6}$ (due to absence of GWS SNPs ${ }^{28-30}$ ), 
medRxiv preprint doi: https://doi.org/10.1101/2021.02.11.21251581; this version posted February 12, 2021. The copyright holder for this preprint

(which was not certified by peer review) is the author/funder, who has granted medRxiv a license to display the preprint in perpetuity.

This article is a US Government work. It is not subject to copyright under 17 USC 105 and is also made available for use under a CCO license.

clumped, respectively, at LD $r^{2}=.001$ and a distance of $10000 \mathrm{~kb}$ (Table 3 in the Supplement).

Alcohol consumption. We included three instrument sets related to alcohol use: drinks per week, ${ }^{31}$ frequency of binge drinking (consuming six or more units of alcohol per occasion), ${ }^{32}$ and AUD. Drinks per week instruments were obtained from the GSCAN GWAS meta-analysis of 29 cohorts (941 280 individuals; demographics not available) of predominantly white European ancestry. ${ }^{31}$ Given the varied cohort methods used to measure alcohol consumption (binned, normalized, etc.), the data was log transformed: thus, the effect estimate is measured in log transformed drinks per week. ${ }^{31}$ To ensure independence, we included all SNPs associated at conventional genome-wide significance (GWS) $\left(P<5 \times 10^{-8}\right)$ and clumped at linkage disequilibrium (LD) $r^{2}=.001$ and a distance of 10000 kilobase $(\mathrm{kb})$ (Table 4 in the Supplement).

For the instrument set assessing frequency of consuming six or more drinks (binge drinking), we used Alcohol Use Disorder Inventory Test (AUDIT) question 3 ("How often do you have six or more drinks on one occasion?") derived from the Neale Lab GWAS results from 143658 UKB participants of European ancestry. ${ }^{32}$ For the AUD instrument set, we used the Psychiatric Genomics Consortium (PGC) GWAS meta-analysis of 28 cohorts (51.6 percent female, 8485 cases, 20657 controls) of predominantly European ancestry. ${ }^{33}$ AUD was diagnosed by either clinician rating or semi-structured interview using DSM-IV criteria including the presence of at least three of seven alcohol-related symptoms (withdrawal, drinking larger amounts/drinking for longer time; tolerance; desire or attempts to cut down drinking; giving up important activities to drink; time related to drinking; or continued alcohol consumption despite psychological and/or physical problems ${ }^{34}$ ). To ensure independence, we included all SNPs associated at $P<5 \times 10^{-6}$ (due to absence of GWS SNPs ${ }^{28-30}$ ) and clumped at LD $r^{2}=.001$ and a distance of $10000 \mathrm{~kb}$ (Table 2 in the Supplement).

For the multivariable MR (MVMR) analyses, we concatenated independent instrument sets for alcohol use, cannabis use and lifetime smoking, and AUD, CUD, and lifetime smoking (clumping the resulting two MV instrument sets to exclude intercorrelated SNPs with pairwise LD $r^{2}>.001$ ), giving us 141 and $126 \mathrm{MV}$ instruments, respectively. $F$ statistics for the unconditional instruments were strong ( $>10$, Tables 3-5 in the Supplement). We were unable to calculate conditional $F$ statistics to assess the strength of the multivariable instrument sets: SVMR statistical methods recently extended to two sample MVMR are appropriate only for nonoverlapping exposure summary level data sources; when overlapping, the requisite pairwise covariances between SNP associations are determinable only using individual level data. ${ }^{35}$

COVID-19 outcomes. We used summary GWAS statistics from the COVID-19 Host Genetics Initiative (COVID-19 hg) meta-analysis Round 4 release data (20 October 2020)

(https://www.covid19hg.org/results) ${ }^{36}$ for 9 COVID-19 phenotypes in predominantly European ancestry cohorts (COVID-19 HG coding; $\mathrm{N}$ cases; $\mathrm{N}$ controls; demographics not available): very severe respiratory confirmed COVID-19 versus population (A2_ALL; 4 933; 623 902); very hospitalized COVID-19 versus not hospitalized COVID-19 (B1_ALL; 2 430; 8 478); hospitalized COVID-19 versus population (B2_ALL; 7 885; 961 804); very severe hospitalized COVID-19 versus population European cohorts only (B2_ALL_EUR; 6 406; 902 088); COVID- 
medRxiv preprint doi: https://doi.org/10.1101/2021.02.11.21251581; this version posted February 12, 2021. The copyright holder for this preprint

(which was not certified by peer review) is the author/funder, who has granted medRxiv a license to display the preprint in perpetuity.

This article is a US Government work. It is not subject to copyright under 17 USC 105 and is also made available for use under a CCO license.

19 versus lab/self-reported negative COVID-19 test (C1; 11 085; 116 794); COVID-19 versus population (C2_ALL; 17 965; 1370 547); COVID-19 versus population European ancestry only (C2_ALL_EUR; 14 134; 1284 876); and predicted COVID-19 from self-reported symptoms versus predicted/self-reported negative (D1_ALL, 3 204; 35 728) (Table 1 in the Supplement).

Other respiratory infection and disease outcomes. We used data from FinnGen project Datafreeze 3 for additional respiratory-related outcomes (Table 1 in the Supplement) ${ }^{37}$. Detailed documentation is provided on the FinnGen study website (https://finngen.gitbook.io/documentation/). FinnGen is a public-private partnership incorporating genetic data for disease endpoints from Finnish biobanks and Finnish health registry EHRs. ${ }^{37}$ FinnGen Datafreeze 3 samples included only European ancestry participants; samples sizes ranged from 116335 (acute nasopharyngitis) to 135638 (acute URIs, asthmarelated infections, asthma-related pneumonia or sepsis, bronchitis, chronic LRIs, and influenza and pneumonia) (Figure 1; Table 1 in the Supplement).

Sample independence. Participant overlap in samples used to estimate genetic associations between exposures and outcomes can increase weak instrument bias (WIB) in MR analyses, ${ }^{38,39}$ but to a lesser extent with large biobank samples (including UKB and deCODE). ${ }^{40}$ Given the large size of the overlapping UKB and deCODE cohorts (Table 1 in the Supplement) and the strength of the instruments in both directions ( $F$ statistics > 10; Tables 2-4 in the Supplement), considerable WIB would not be expected. ${ }^{39,40}$

Statistical and sensitivity analyses. For SVMR analyses, we used inverse-variance weighted MR (MR IVW) along with MR-Egger, weighted median, and weighted mode methods, to assess evidence of causal effects of each of alcohol, cannabis and tobacco use and dependence on infectious disease outcomes; also, to detect the sensitivity of the results to different patterns of violations of IV assumptions, ${ }^{41}$ as consistency of results across methods strengthens an inference

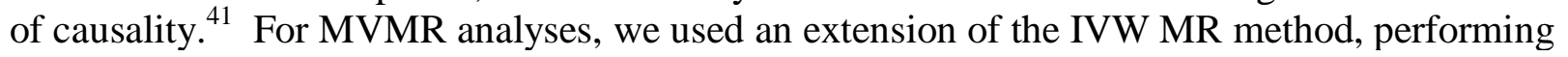
multivariable weighted linear regression (variants uncorrelated, random-effects model) with the intercept term set to zero. ${ }^{38,42}$ We used an extension of the MR-Egger method to correct for both measured and unmeasured pleiotropy ${ }^{43}$. To evaluate heterogeneity in instrument effects, which may indicate potential violations of the IV assumptions underlying two-sample MR. ${ }^{44}$ we used the MR Egger intercept test, ${ }^{44}$ and the Cochran heterogeneity test, ${ }^{45}$ and multivariable extensions thereof. ${ }^{42,43}$ The MR pleiotropy residual sum and outlier (MR-PRESSO) global test, and multivariable extension thereof ${ }^{4 \overline{6}}$, were used to facilitate identification and removal of outlier instruments to correct potential directional horizontal pleiotropy and resolve detected heterogeneity. For the SVMR, we used the Steiger directionality test tested the causal direction between the hypothesized exposure and outcomes. ${ }^{47}$ Analyses were carried out using TwoSampleMR, version 0.5.5, ${ }^{41}$ MendelianRandomization, version 0.5.0, and MR PRESSO, version $1.0,{ }^{46}$ in the $\mathrm{R}$ environment, version 4.0.2.

Reported results and interpretation of findings. SVMR and MVMR results with test statistics both before and after outlier correction are presented in Tables 7-11 in the Supplement. MR IVW (MR PRESSO outlier corrected) odds ratios (OR) with 95\% CI, per unit increase in the exposures (e.g. per unit increase of log-transformed alcoholic drinks per week or lifetime smoking index), with $P$-value, are presented in Tables 1-2. 
medRxiv preprint doi: https://doi.org/10.1101/2021.02.11.21251581; this version posted February 12, 2021. The copyright holder for this preprint (which was not certified by peer review) is the author/funder, who has granted medRxiv a license to display the preprint in perpetuity. This article is a US Government work. It is not subject to copyright under 17 USC 105 and is also made available for use under a CCO license.

While we caution against interpreting the results based solely upon a $P$-value threshold, ${ }^{48}$ we generally use a two-sided $\alpha$ of .007 based on comparing 7 COVID-19 outcomes and .004 based on comparing14 FinnGen infectious respiratory diseases as a heuristic that allows for follow-up analyses for a plausible number of findings. In assessing consistency and robustness, we looked for estimates substantially agreeing in direction and magnitude (overlapping confidence intervals) across then four complementary MR methods used. We underscore evidence strength based upon the effect magnitude and direction, the $95 \%$ confidence interval of that effect, and the $P$-value.

\section{RESULTS}

COVID-19 disease outcomes. In SVMR, genetically predicted lifetime smoking was found to be associated with increased risk for "hospitalized COVID-19 versus population" (OR 4.039, 95\% CI 2.335-6.985, $P$-value $=5.93 \times 10^{-7}$ ) and "very severe hospitalized COVID-19 versus population (predominantly European)" (OR 3.091, 95\% CI 1.883-5.092, $P$-value $=8.40 \times 10^{-6}$ ), with consistent magnitude and direction across all four SVMR methods (Table 1; Table 8 in the Supplement). Controlling for AUD and CUD (Table 1; Table 10 in the Supplement), and alternatively for alcohol and cannabis use (Table 1; Table 11 in the Supplement), in MVMR, genetically predicted lifetime smoking was still found to be associated with increased risk for both COVID-19 outcomes, with increased point estimate magnitudes compared to SVMR ("hospitalized COVID-19 versus population" OR 4.457, 95\% CI 2.287-8.687, $P$-value = $1.14 \times 10^{-5}$ (controlling for other substance dependence/use disorder), and OR 4.716, 95\% CI 2.580-8.621, $P$-value $=4.66 \times 10^{-7}$ (controlling for other substance use); and "very severe hospitalized COVID-19 versus population (predominantly European)", OR 3.152, 95\% CI 1.7265.757, $P$-value $=1.86 \times 10^{-4}$ (controlling for other substance dependence/use disorder), and OR $3.630,95 \%$ CI 2.126-6.199, $P$-value $=2.33 \times 10^{-6}$ (controlling for other substance use) $)$, with consistent magnitude and direction across the two MVMR methods.

Genetically predicted AUD but not alcohol consumption (drinks per week) was found to be associated with increased risk for "COVID-19 versus self-reported negative" in SVMR (OR $1.128,95 \%$ CI 1.039-1.226, $P$-value $=.004)$; in MVMR, controlling for cannabis use disorder and lifetime smoking, that association remained although with a lesser $P$-value (OR 1.145, 95\% CI 1.033-1.269, $P$-value $=.010$ ) (Tables 8 and 10 in the Supplement). In contrast, genetically predicted cannabis use and CUD were not found to be associated with risk of any COVID-19 disease outcome (Tables 7 and 9-11 in the Supplement).

FinnGen infectious disease outcomes. In SVMR, genetically predicted lifetime smoking was found to be associated with increased risk for: Bronchitis (OR 1.558, 95\% CI 1.196-2.030, $P$ value $=.001)$, all pneumoniae $\left(\right.$ OR $1.589,95 \%$ CI $1.214-2.078, P$-value $\left.=7.33 \times 10^{-4}\right)$, bacterial pneumonia (OR 2.083, 95\% CI 1.352-3.208, $P$-value $=8.70 \times 10^{-4}$ ), acute upper respiratory infections (OR $1.550,95 \%$ CI 1.223-1.962, $P$-value $=2.80 \times 10^{-4}$, chronic lower respiratory diseases $\left(\mathrm{OR} 2.303,95 \%\right.$ CI 1.713-3.097, $P$-value $\left.=3.40 \times 10^{-8}\right)$, asthma related infections $(\mathrm{OR}$ $1.573,95 \%$ CI $1.309-1.890, P$-value $\left.=1.37 \times 10^{-6}\right)$, asthma related acute respiratory infections $\left(\right.$ OR $1.665,95 \%$ CI 1.325-2.093, $P$-value $\left.=1.26 \times 10^{-5}\right)$, asthma-related pneumonia $($ OR 1.589 , 95\% CI 1.214-2.078, $P$-value $\left.=1.67 \times 10^{-4}\right)$, asthma/ COPD $($ OR 2.069, 95\% CI 1.471-2.909, $P$ value $\left.=2.90 \times 10^{-5}\right)$, and asthma-related pneumonia or sepsis (OR 1.580, 95\% CI 1.213-2.060, $P$ - 
medRxiv preprint doi: https://doi.org/10.1101/2021.02.11.21251581; this version posted February 12, 2021. The copyright holder for this preprint

(which was not certified by peer review) is the author/funder, who has granted medRxiv a license to display the preprint in perpetuity.

This article is a US Government work. It is not subject to copyright under 17 USC 105 and is also made available for use under a CCO license.

value $=7.05 \times 10^{-4}$ ). In MVMR, controlling for AUD and CUD, and, alternatively, for alcohol and cannabis use, lifetime smoking was still found to be associated with increased risk for these outcomes, with consistent magnitude and direction across SVMR and MVMR outcomes but with $P$-values attenuated towards the null ((Tables 10-11 in the Supplement)).

Genetically predicted CUD, but not cannabis use, was found associated with increased risk for chronic lower respiratory diseases (including bronchitis and asthma COPD) (OR 1.078, 95\% CI $1.020-1.128, P$-value $=.007)$; bronchitis $($ OR $1.061,95 \%$ CI 1.003-1.124, $P$-value $=.040)$; asthma related acute respiratory infections (OR 1.053, 95\% CI 1.007-1.102, $P$-value $=.023$ ); asthma related pneumonia (OR 1.070, 95\% CI 1.007-1.137, $P$-value $=.028)$; and asthma related sepsis or pneumonia (OR 1.064, 95\% CI 1.003-1.127, $P$-value $=.038)$ (Table 9 in the

Supplement). Controlling for AUD and lifetime smoking in MVMR, these associations attenuated towards the null (Table 10 in the Supplement). In contrast, genetically predicted alcohol use and AUD were not found to be associated with risk of any FinnGen infectious disease outcome (Tables 7 and 9-11 in the Supplement).

Evidence of heterogeneity but not directional pleiotropy was found only for lifetime smoking on chronic lower respiratory diseases across SVMR and MVMR analyses; and also for lifetime smoking on asthma/COPD in the MVMR analyses controlling for AUD and CUD. Steiger directionality analyses suggests correct causal direction for all analyses (Tables 7-11 in the Supplement).

\section{DISCUSSION}

Using large summary-level GWAS data and complementary two-sample MR methods, we show that the genetic liability for tobacco smoking has potential causal relationships with several respiratory infection and disease outcomes, including COVID-19. These tobacco smokingrespiratory findings were supported by multivariable MR analyses accounting for alcohol and cannabis use and abuse, which in addition the broadly consistent IVW results (within the IVW MR 95\% confidence interval but typically less precise) with estimates from the weighted median, weighted mode, and MR Egger sensitivity analyses strengthens causal inference. Further, in single variable MR, we identify potential adverse impact CUD on lower respiratory infection, the common cold, and several asthma-related infections, suggesting evidence for a dose-dependent impact of cannabis use where heavy cannabis use may be harmful to the respiratory system. In parallel, we find little evidence for an alcohol-respiratory infection relationship suggesting that previous observational data may be due to confounding.

Our COVID-19 results extend recent MR studies showing adverse effects of smoking on COVID-19 risk $^{49}$ by accounting for highly comorbid alcohol consumption, cannabis use, and SUDs, which when combined with reports suggesting smoking intensifies the severity of COVID-19 symptoms, ${ }^{50,51}$ the risk for being admitted to an intensive care unit or requiring ventilation, ${ }^{51}$ and recent transcriptomics-based work showing that smoking may increase the expression of angiotensin converting enzyme 2 (ACE2), the putative receptor for severe acute respiratory syndrome coronavirus 2 (SARS-CoV-2) (the virus that causes COVID-19), ${ }^{52}$ suggests smoking may be an important modifiable risk factor for COVID-19 risk. 
medRxiv preprint doi: https://doi.org/10.1101/2021.02.11.21251581; this version posted February 12, 2021. The copyright holder for this preprint

(which was not certified by peer review) is the author/funder, who has granted medRxiv a license to display the preprint in perpetuity.

This article is a US Government work. It is not subject to copyright under 17 USC 105 and is also made available for use under a CCO license.

Our genetics-based findings support and extend the observational literature identifying tobacco smoking as a risk factor for respiratory infection and diseases, ${ }^{9,53,54}$ and add to the recent MR literature identifying potential causal links of smoking with reduced lung function ${ }^{55}$, lung cancer, ${ }^{56}$ and increased mortality due to respiratory disease. ${ }^{57}$ Potential mechanisms by which smoking increases respiratory infection risk include structural changes to the respiratory tract and a dysregulated cellular and humoral immune response, including peribronchiolar inflammation, decreased levels of circulating immunoglobulins, and changes to pathogen adherence. ${ }^{53}$ For example, smoking has been shown to stimulate the release of catecholamine and corticosteroids, which may, in turn, increase circulating $\mathrm{CD}^{+}$lymphocytes and suppress the host defense against infections. ${ }^{53}$ Notably, many immunological effects related to smoking may resolve within six weeks of smoking cessation, ${ }^{53}$ which suggests that smoking cessation programs may have an important impact on reducing respiratory infections.

Regarding cannabis use, to our knowledge this is the first MR study to investigate the role of cannabis use in respiratory infections, and while we failed to find evidence of any relationships, smoking cannabis, like tobacco smoking, may prompt the onset of coughing, which could consequently increase viral transmission, or may exacerbate possibly respiratory symptoms. As cannabis is the most used drug worldwide -an estimated 188 million recreational users worldwide $^{58}$ - this aspect of cannabis use may have important implications for the spread of COVID-19. In contrast, the single-variable MR CUD results demonstrated adverse effects on several respiratory outcomes, but not COPD, which supports the existing literature; ${ }^{59-61}$ however, accounting for lifetime tobacco smoking attenuated highlighting the complex nature of these relationships. Further, habitual cannabis smoking may have several effects on respiratory and immune systems that may impact respiratory infection susceptibility: For example, structural abnormalities in alveolar macrophages and coincident dysregulated cytokine production and antimicrobial activity have been reported. ${ }^{61}$ While our study provides preliminary genetic evidence suggesting potential causal relationships between heavy cannabis use and respiratory infection, additional triangulating lines of evidence (i.e., immune monitoring studies), are required to further elucidate the CUD-respiratory infection relationship. However, the toxin and irritant profiles of cannabis and tobacco smoke are similar, ${ }^{11}$ which suggests the direct route of administration via inhalation for these substances and may result in dysregulated pulmonary physiology which may, in turn, increase infection risk.

In contrast to our tobacco smoking findings, we failed to find genetic evidence of respiratory implications due to alcohol consumption not meeting threshold of AUD, or binge drinking, suggesting that previous observational literature may be due to confounding from other comorbid behaviors - such as smoking - that may be the true causal risk factors for respiratory infections. For example, observational and genetic evidence have shown a strong association between alcohol consumption and smoking: It has been estimated that $85 \%$ of smokers consume alcohol $^{62-64}$ and alcohol drinkers are $75 \%$ more likely than abstainers to smoke ${ }^{65}$. Therefore, it is possible that the observational study-based alcohol-respiratory infection links may be due, instead, to tobacco smoking; however, future work will be needed to confirm this hypothesis. In addition, it is important to note that our results should not be interpreted as suggesting that alcohol does not impact overall lung health and structure, which has been previously reported. ${ }^{7}$ Further, while we failed to find evidence that weekly alcohol consumption impacted COVID-19 
medRxiv preprint doi: https://doi.org/10.1101/2021.02.11.21251581; this version posted February 12, 2021. The copyright holder for this preprint

(which was not certified by peer review) is the author/funder, who has granted medRxiv a license to display the preprint in perpetuity.

This article is a US Government work. It is not subject to copyright under 17 USC 105 and is also made available for use under a CCO license.

risk, the Centers for Disease Control recently showed that dining at on-site locations, such as restaurants and bars, is associated with increased COVID-19 risk, ${ }^{66}$ and given that alcohol consumption may lower inhibition and increase impulsivity, ${ }^{67}$ individuals consuming alcohol may take social distancing less seriously, and thereby unintentionally spread the SARS-CoV-2 virus.

This study has several strengths including the use of multiple alcohol consumption and cannabis use variables, which enabled us to evaluate various dimensions of substance use and abuse and identify possible causal relationships of substance use disorders and respiratory outcomes. In addition, our main single variable analyses included multiple MR methods, each relying on orthogonal assumptions, provides confidence in robustness of the results and strengthens causal inference. $^{68}$ Further, our multivariable two-sample MR design, the most appropriate design given the strong correlation between tobacco smoking, alcohol consumption and cannabis use, yielding estimates that account for these correlated behaviors for each exposure on COVID-19 risk and other respiratory outcomes. ${ }^{69}$

This study also has limitations: For example, like existing self-reported substance use literature, these exposures may be either under- or over-reported. ${ }^{70}$ Because many of the datasets included UK Biobank participants, who are more educated, with healthier lifestyles, and fewer health problems than the UK population, ${ }^{71}$ which may limit the applicability of our findings to other populations. Regarding our mainly null alcohol-respiratory infection results, it is possible that alcohol may have indirect impact on infection risk through a modified immune response, ${ }^{72}$ or other system dysregulation, that may modulate infection risk that we were not able to directly assess. Further, while we found some evidence that AUD may increase the risk for COVID-19; the largely null other current AUD findings does not support a broader AUD-respiratory disease relationship. However, like other recent psychiatric MR studies where the exposure instruments included a relaxed statistical threshold, our binge drinking and AUD instruments were comprised of independent SNPs associated with the respective drinking behavior (i.e., P-value $<5 \times 10^{-6}$ ) for SNP inclusion due to the lack of conventionally GWS SNPs (P-value $<5 \times 10^{-8}$ ), ${ }^{29,30}$ which may impact the results. Because heavy alcohol consumption and AUD have been previously linked with acute respiratory distress syndrome ${ }^{10}$ - one of the most severe complications of COVID$19{ }^{73}$ future studies re-evaluating the links between heavy alcohol consumption and AUD when better powered GWAS data becomes available.

In addition, the included samples were comprised of primarily white individuals of European ancestry, and research has shown strong racial, ethnic, and socioeconomic disparities in COVID19 risk, and severity. ${ }^{74-76}$ Therefore, we caution the generalization of these findings and urge future work to investigate these relationships using a genetics-based approach in other populations when the data becomes available. Another limitation is the overlap of the UKB participants between the alcohol consumption, lifetime smoking, and COVID-19 outcomes, which may bias resulting estimates; ${ }^{39}$ however, any bias would likely be minimal. ${ }^{39}$ It has been also shown that two-sample MR may be safely used in single samples provided the data is derived from large biobanks (i.e., the UKB, FinnGen, etc.,.). ${ }^{77}$

In conclusion, our data provide genetic evidence of adverse relationships between smoking and many respiratory-related disease outcomes ranging from the common cold to severe COVID-19, 
medRxiv preprint doi: https://doi.org/10.1101/2021.02.11.21251581; this version posted February 12, 2021. The copyright holder for this preprint (which was not certified by peer review) is the author/funder, who has granted medRxiv a license to display the preprint in perpetuity. This article is a US Government work. It is not subject to copyright under 17 USC 105 and is also made available for use under a CCO license.

which suggests prevention programs aimed at smoking cessation and prevention may have public health and clinical benefits. We also observed a potential dose-dependent relationship where heavy substance use - as indicated by CUD - but not general cannabis use, was linked with several respiratory infections, suggesting heavy cannabis use may have a harmful impact on respiratory infections, which may have important respiratory-related consequences given the increasingly permissive cannabis-use laws.

\section{ACKNOWLEGEMENTS}

We want to acknowledge the participants and investigators of the many studies used in this research without whom this effort would not be possible: the COVID-19 Host Genetics Initiative and the contributors thereto specified at http://www.covid19hg.org/acknowledgments.html; FinnGen study; and the UK Biobank. We also want to acknowledge the Medical Research Council Integrative Epidemiology Unit (MRC-IEU, University of Bristol, UK), especially the developers of the MRC-IEU UK Biobank GWAS Pipeline. This work was supported by the National Institutes of Health (NIH) intramural funding [ZIA-AA000242 to F.W.L]; Division of Intramural Clinical and Biological Research of the National Institute on Alcohol Abuse and Alcoholism (NIAAA).

\section{CONFLICTS OF INTEREST}

We report no conflicts of interest.

\section{DATA AVAILABILITY}

All analyses were based upon publicly available data. COVID-19 GWAS summary-level data is available at https://www.covid19hg.org/results/. FinnGen data are available at https://www.finngen.fi/en; lifetime smoking at https://data.bris.ac.uk/data/dataset/10i96zb8gm0j81yz0q6ztei23d; alcohol drinks per week data at: https://genome.psych.umn.edu/index.php/GSCAN; frequency of consuming $>6$ drinks per occasion data are available at: http://www.nealelab.is/uk-biobank; cannabis use disorder and alcohol dependence data are available through the Psychiatric Genomics Consortium data portal: https://www.med.unc.edu/pgc/download-results/; and the cannabis use data are available through the International Cannabis Consortium at: https://www.ru.nl/bsi/research/group-pages/substanceuse-addiction-food-saf/vm-saf/genetics/international-cannabis-consortium-icc/.

\section{REFERENCES}

1. Puntmann VO, Carerj ML, Wieters I, et al. Outcomes of Cardiovascular Magnetic Resonance Imaging in Patients Recently Recovered From Coronavirus Disease 2019 (COVID-19). JAMA Cardiology. 2020. 
medRxiv preprint doi: https://doi.org/10.1101/2021.02.11.21251581; this version posted February 12, 2021. The copyright holder for this preprint

(which was not certified by peer review) is the author/funder, who has granted medRxiv a license to display the preprint in perpetuity. This article is a US Government work. It is not subject to copyright under 17 USC 105 and is also made available for use under a CCO license.

2. Shi S, Qin M, Shen B, et al. Association of Cardiac Injury With Mortality in Hospitalized Patients With COVID-19 in Wuhan, China. JAMA Cardiol. 2020;5(7):802-810.

3. Nishiga M, Wang DW, Han Y, Lewis DB, Wu JC. COVID-19 and cardiovascular disease: from basic mechanisms to clinical perspectives. Nature Reviews Cardiology. 2020;17(9):543-558.

4. Troeger C, Blacker B, Khalil IA, et al. Estimates of the global, regional, and national morbidity, mortality, and aetiologies of lower respiratory infections in 195 countries, 1990\&\#x2013;2016: a systematic analysis for the Global Burden of Disease Study 2016. The Lancet Infectious Diseases. 2018;18(11):1191-1210.

5. Soriano JB, Abajobir AA, Abate KH, et al. Global, regional, and national deaths, prevalence, disability-adjusted life years, and years lived with disability for chronic obstructive pulmonary disease and asthma, 1990\&\#x2013;2015: a systematic analysis for the Global Burden of Disease Study 2015. The Lancet Respiratory Medicine. 2017;5(9):691-706.

6. Adams PF, Hendershot GE, Marano MA. Current estimates from the National Health Interview Survey, 1996. Vital Health Stat 10. 1999(200):1-203.

7. Simet SM, Sisson JH. Alcohol's Effects on Lung Health and Immunity. Alcohol research : current reviews. 2015;37(2):199-208.

8. Tashkin DP. Effects of Marijuana Smoking on the Lung. Annals of the American Thoracic Society. 2013;10(3):239-247.

9. Jiang $C$, Chen $Q$, Xie M. Smoking increases the risk of infectious diseases: A narrative review. Tob Induc Dis. 2020;18:60-60.

10. Simou E, Leonardi-Bee J, Britton J. The Effect of Alcohol Consumption on the Risk of ARDS: A Systematic Review and Meta-Analysis. Chest. 2018;154(1):58-68.

11. Moir D, Rickert WS, Levasseur $G$, et al. A comparison of mainstream and sidestream marijuana and tobacco cigarette smoke produced under two machine smoking conditions. Chem Res Toxicol. 2008;21(2):494-502.

12. Ribeiro LIG, Ind PW. Effect of cannabis smoking on lung function and respiratory symptoms: a structured literature review. npj Primary Care Respiratory Medicine. 2016;26(1):16071.

13. Trevejo-Nunez G, Kolls JK, de Wit M. Alcohol Use As a Risk Factor in Infections and Healing: A Clinician's Perspective. Alcohol research : current reviews. 2015;37(2):177184.

14. Farhoudian A, Radfar SR, Mohaddes Ardabili H, et al. A global survey on changes in the supply, price and use of illicit drugs and alcohol, and related complications during the 2020 COVID-19 pandemic. medRxiv. 2020:2020.2007.2016.20155341.

15. Services. TSAaMHSASotUSDoHaH. T Key Substance Use and Mental Health Indicators in the United States: results from the 2018 National Survey on Drug Use and Health.

https://www.samhsa.gov/data/sites/default/files/cbhsqreports/NSDUHNationalFindingsReport2018/NSDUHNationalFindingsReport2018.pdf. Published 2018 Accessed December 52020

16. Wang QQ, Kaelber DC, Xu R, Volkow ND. COVID-19 risk and outcomes in patients with substance use disorders: analyses from electronic health records in the United States. Molecular Psychiatry. 2020. 
medRxiv preprint doi: https://doi.org/10.1101/2021.02.11.21251581; this version posted February 12, 2021. The copyright holder for this preprint

(which was not certified by peer review) is the author/funder, who has granted medRxiv a license to display the preprint in perpetuity. This article is a US Government work. It is not subject to copyright under 17 USC 105 and is also made available for use under a CCO license.

17. Smith GD, Ebrahim S. Epidemiology-is it time to call it a day? International journal of epidemiology. 2001;30(1):1-11.

18. Smith GD, Ebrahim S. 'Mendelian randomization': can genetic epidemiology contribute to understanding environmental determinants of disease? International journal of epidemiology. 2003;32(1):1-22.

19. Evans DM, Davey Smith G. Mendelian Randomization: New Applications in the Coming Age of Hypothesis-Free Causality. Annu Rev Genomics Hum Genet. 2015;16:327-350.

20. Sekula P, Del Greco M F, Pattaro C, Köttgen A. Mendelian Randomization as an Approach to Assess Causality Using Observational Data. Journal of the American Society of Nephrology. 2016;27(11):3253-3265.

21. Goldstein CE, Weijer C, Brehaut JC, et al. Ethical issues in pragmatic randomized controlled trials: a review of the recent literature identifies gaps in ethical argumentation. BMC Med Ethics. 2018;19(1):14-14.

22. Davey Smith G, Hemani G. Mendelian randomization: genetic anchors for causal inference in epidemiological studies. Hum Mol Genet. 2014;23(R1):R89-98.

23. Yarmolinsky J, Bull CJ, Vincent EE, et al. Association Between Genetically Proxied Inhibition of HMG-COA Reductase and Epithelial Ovarian Cancer. Jama. 2020;323(7):646655.

24. Pingault J-B, O'Reilly PF, Schoeler T, Ploubidis GB, Rijsdijk F, Dudbridge F. Using genetic data to strengthen causal inference in observational research. Nature Reviews Genetics. 2018;19(9):566-580.

25. Wootton RE, Richmond RC, Stuijfzand BG, et al. Evidence for causal effects of lifetime smoking on risk for depression and schizophrenia: a Mendelian randomisation study. Psychological Medicine. 2020;50(14):2435-2443.

26. Pasman JA, Verweij KJH, Gerring Z, et al. GWAS of lifetime cannabis use reveals new risk loci, genetic overlap with psychiatric traits, and a causal effect of schizophrenia liability. Nature Neuroscience. 2018;21(9):1161-1170.

27. Johnson EC, Demontis D, Thorgeirsson TE, et al. A large-scale genome-wide association study meta-analysis of cannabis use disorder. The Lancet Psychiatry. 2020;7(12):10321045.

28. Richardson TG, Harrison S, Hemani G, Davey Smith G. An atlas of polygenic risk score associations to highlight putative causal relationships across the human phenome. elife. 2019;8:e43657.

29. Rosoff DB, Smith GD, Lohoff FW. Prescription Opioid Use and Risk for Major Depressive Disorder and Anxiety and Stress-Related Disorders: A Multivariable Mendelian Randomization Analysis. JAMA Psychiatry. 2020.

30. Hartwig FP, Borges MC, Horta BL, Bowden J, Davey Smith G. Inflammatory Biomarkers and Risk of Schizophrenia: A 2-Sample Mendelian Randomization Study. JAMA Psychiatry. 2017;74(12):1226-1233.

31. Liu M, Jiang $Y$, Wedow $R$, et al. Association studies of up to 1.2 million individuals yield new insights into the genetic etiology of tobacco and alcohol use. Nature Genetics. 2019;51(2):237-244.

32. Neale-Lab. UK Biobank GWAS. http://www.nealelab.is/uk-biobank/. Published 2018. Accessed June 2019. 
medRxiv preprint doi: https://doi.org/10.1101/2021.02.11.21251581; this version posted February 12, 2021. The copyright holder for this preprint

(which was not certified by peer review) is the author/funder, who has granted medRxiv a license to display the preprint in perpetuity. This article is a US Government work. It is not subject to copyright under 17 USC 105 and is also made available for use under a CCO license.

33. Walters RK, Polimanti R, Johnson EC, et al. Transancestral GWAS of alcohol dependence reveals common genetic underpinnings with psychiatric disorders. Nature Neuroscience. 2018;21(12):1656-1669.

34. Pub AP. Diagnostic and Statistical Manual of Mental Disorders: DSM-IV-TR. Washington, DC2000.

35. Sanderson E, Spiller W, Bowden J. Testing and Correcting for Weak and Pleiotropic Instruments in Two-Sample Multivariable Mendelian Randomisation. bioRxiv (preprint). 2020:2020.2004.2002.021980.

36. The C-HGI. The COVID-19 Host Genetics Initiative, a global initiative to elucidate the role of host genetic factors in susceptibility and severity of the SARS-CoV-2 virus pandemic. European Journal of Human Genetics. 2020;28(6):715-718.

37. FinnGen. FinnGen Documentation of the R3 release. https://finngen.gitbook.io/documentation/. Published 2020. Accessed June 18, 2020.

38. Burgess S, Thompson SG. Multivariable Mendelian randomization: the use of pleiotropic genetic variants to estimate causal effects. Am J Epidemiol. 2015;181(4):251-260.

39. Burgess S, Davies NM, Thompson SG. Bias due to participant overlap in two-sample Mendelian randomization. Genet Epidemiol. 2016;40(7):597-608.

40. Minelli C, Fabiola Del Greco M, van der Plaat DA, Bowden J, Sheehan NA, Thompson J. The use of two-sample methods for Mendelian randomization analyses on single large datasets. bioRxiv. 2020:2020.2005.2007.082206.

41. Hemani G, Zheng J, Elsworth B, et al. The MR-Base platform supports systematic causal inference across the human phenome. Elife. 2018;7.

42. Yavorska OO, Burgess S. MendelianRandomization: an R package for performing Mendelian randomization analyses using summarized data. International journal of epidemiology. 2017;46(6):1734-1739.

43. Rees JMB, Wood AM, Burgess S. Extending the MR-Egger method for multivariable Mendelian randomization to correct for both measured and unmeasured pleiotropy. Stat Med. 2017;36(29):4705-4718.

44. Bowden J, Del Greco MF, Minelli C, Smith GD, Sheehan N, Thompson J. A framework for the investigation of pleiotropy in two-sample summary data Mendelian randomization. Statistics in Medicine. 2017;36(11):1783-1802.

45. Bowden J, Del Greco MF, Minelli C, et al. Improving the accuracy of two-sample summary-data Mendelian randomization: moving beyond the NOME assumption. International journal of epidemiology. 2019;48(3):728-742.

46. Verbanck M, Chen CY, Neale B, Do R. Detection of widespread horizontal pleiotropy in causal relationships inferred from Mendelian randomization between complex traits and diseases (vol 50, 693, 2018). Nature Genetics. 2018;50(8):1196-1196.

47. Hemani G, Tilling K, Smith GD. Orienting the causal relationship between imprecisely measured traits using GWAS summary data. Plos Genet. 2017;13(11).

48. Amrhein V, Greenland S, McShane B. Scientists rise up against statistical significance. Nature. 2019;567(7748):305-307.

49. Ponsford MJ, Gkatzionis A, Walker VM, et al. Cardiometabolic Traits, Sepsis, and Severe COVID-19. Circulation. 2020;142(18):1791-1793. 
medRxiv preprint doi: https://doi.org/10.1101/2021.02.11.21251581; this version posted February 12, 2021. The copyright holder for this preprint

(which was not certified by peer review) is the author/funder, who has granted medRxiv a license to display the preprint in perpetuity. This article is a US Government work. It is not subject to copyright under 17 USC 105 and is also made available for use under a CCO license.

50. Polverino F, Stern DA, Ruocco G, et al. Comorbidities, Cardiovascular Therapies, and COVID-19 Mortality: A Nationwide, Italian Observational Study (ItaliCO). Front Cardiovasc Med. 2020;7:585866.

51. Vardavas $\mathrm{Cl}$, Nikitara K. COVID-19 and smoking: A systematic review of the evidence. Tob Induc Dis. 2020;18:20-20.

52. Cai G, Bossé Y, Xiao F, Kheradmand F, Amos Cl. Tobacco Smoking Increases the Lung Gene Expression of ACE2, the Receptor of SARS-CoV-2. Am J Respir Crit Care Med. 2020;201(12):1557-1559.

53. Arcavi L, Benowitz NL. Cigarette Smoking and Infection. Archives of Internal Medicine. 2004;164(20):2206-2216.

54. Jayes L, Haslam PL, Gratziou CG, et al. SmokeHaz: Systematic Reviews and Metaanalyses of the Effects of Smoking on Respiratory Health. Chest. 2016;150(1):164-179.

55. Millard LAC, Munafò MR, Tilling K, Wootton RE, Davey Smith G. MR-pheWAS with stratification and interaction: Searching for the causal effects of smoking heaviness identified an effect on facial aging. Plos Genet. 2019;15(10):e1008353.

56. Larsson SC, Carter P, Kar S, et al. Smoking, alcohol consumption, and cancer: A mendelian randomisation study in UK Biobank and international genetic consortia participants. PLoS medicine. 2020;17(7):e1003178-e1003178.

57. Vie G, Wootton RE, Bjørngaard JH, et al. The effect of smoking intensity on all-cause and cause-specific mortality-a Mendelian randomization analysis. International journal of epidemiology. 2019;48(5):1438-1446.

58. Kroon E, Kuhns L, Hoch E, Cousijn J. Heavy cannabis use, dependence and the brain: a clinical perspective. Addiction. 2020;115(3):559-572.

59. Tetrault JM, Crothers K, Moore BA, Mehra R, Concato J, Fiellin DA. Effects of marijuana smoking on pulmonary function and respiratory complications: a systematic review. Arch Intern Med. 2007;167(3):221-228.

60. Bramness JG, von Soest T. A longitudinal study of cannabis use increasing the use of asthma medication in young Norwegian adults. BMC Pulmonary Medicine. 2019;19(1):52.

61. Tashkin DP. Does marijuana pose risks for chronic airflow obstruction? Annals of the American Thoracic Society. 2015;12(2):235-236.

62. Marees AT, Smit DJA, Ong JS, et al. Potential influence of socioeconomic status on genetic correlations between alcohol consumption measures and mental health. Psychol Med. 2019:1-15.

63. Karlsson Linnér R, Biroli $P$, Kong $E$, et al. Genome-wide association analyses of risk tolerance and risky behaviors in over 1 million individuals identify hundreds of loci and shared genetic influences. Nature Genetics. 2019;51(2):245-257.

64. Patten CA, Martin JE, Owen N. Can psychiatric and chemical dependency treatment units be smoke free? Journal of Substance Abuse Treatment. 1996;13(2):107-118.

65. Touchette JC, Lee AM. Assessing alcohol and nicotine co-consumption in mice. Oncotarget. 2017;8(4):5684-5685.

66. Kiva A. Fisher MWT, Leora R. Feldstein, Christopher J. Lindsell, Nathan I. Shapiro, D. Clark Files, Kevin W. Gibbs, Heidi L. Erickson, Matthew E. Prekker, Jay S. Steingrub, Matthew C. Exline, Daniel J. Henning, Jennifer G. Wilson, Samuel M. Brown, Ithan D. 
medRxiv preprint doi: https://doi.org/10.1101/2021.02.11.21251581; this version posted February 12, 2021. The copyright holder for this preprint

(which was not certified by peer review) is the author/funder, who has granted medRxiv a license to display the preprint in perpetuity. This article is a US Government work. It is not subject to copyright under 17 USC 105 and is also made available for use under a CCO license.

Peltan, Todd W. Rice, David N. Hager, Adit A. Ginde, H. Keipp Talbot, Jonathan D. Casey, Carlos G. Grijalva, Brendan Flannery, Manish M. Patel, Wesley H. Self, IVY Network Investigators; CDC COVID-19 Response Team Community and Close Contact Exposures Associated with COVID-19 Among Symptomatic Adults $\geq 18$ Years in 11 Outpatient Health Care Facilities - United States, July 2020. CDC. Morbidity and Mortality Weekly Report (MMWR) Web site. https://www.cdc.gov/mmwr/volumes/69/wr/mm6936a5.htm. Published 2020. Accessed January 5, 2021.

67. Dick DM, Smith $G$, Olausson $P$, et al. Understanding the construct of impulsivity and its relationship to alcohol use disorders. Addict Biol. 2010;15(2):217-226.

68. Gage SH, Bowden J, Smith GD, Munafo MR. Investigating causality in associations between education and smoking: a two-sample Mendelian randomization study. International journal of epidemiology. 2018;47(4):1131-1140.

69. Sanderson E, Davey Smith G, Windmeijer F, Bowden J. An examination of multivariable Mendelian randomization in the single-sample and two-sample summary data settings. International journal of epidemiology. 2018.

70. Rosenman R, Tennekoon V, Hill LG. Measuring bias in self-reported data. Int J Behav Healthc Res. 2011;2(4):320-332.

71. Fry A, Littlejohns TJ, Sudlow C, et al. Comparison of Sociodemographic and HealthRelated Characteristics of UK Biobank Participants With Those of the General Population. American Journal of Epidemiology. 2017;186(9):1026-1034.

72. Szabo G, Saha B. Alcohol's Effect on Host Defense. Alcohol research : current reviews. 2015;37(2):159-170.

73. Fan E, Beitler JR, Brochard L, et al. COVID-19-associated acute respiratory distress syndrome: is a different approach to management warranted? The Lancet Respiratory Medicine. 2020;8(8):816-821.

74. Price-Haywood EG, Burton J, Fort D, Seoane L. Hospitalization and Mortality among Black Patients and White Patients with Covid-19. New England Journal of Medicine. 2020;382(26):2534-2543.

75. Yancy CW. COVID-19 and African Americans. Jama. 2020;323(19):1891-1892.

76. Niedzwiedz CL, O'Donnell CA, Jani BD, et al. Ethnic and socioeconomic differences in SARS-CoV-2 infection: prospective cohort study using UK Biobank. BMC Medicine. 2020;18(1):160.

77. Minelli C, Fabiola Del Greco M, van der Plaat DA, Bowden J, Sheehan NA, Thompson J. The use of two-sample methods for Mendelian randomization analyses on single large datasets. bioRxiv (preprint). 2020:2020.2005.2007.082206. 
medRxiv preprint doi: https://doi.org/10.1101/2021.02.11.21251581; this version posted February 12, 2021. The copyright holder for this preprint

(which was not certified by peer review) is the author/funder, who has granted medRxiv a license to display the preprint in perpetuity.

This article is a US Government work. It is not subject to copyright under 17 USC 105 and is also made available for use under a CCO license.

\section{Exposure and Outcome Data}

\begin{tabular}{|c|}
\hline $\begin{array}{l}\text { Substance use exposures: } \\
\text { - Lifetime smoking }(\mathrm{N}=462,690) \\
\text { - Cannabis use }(\mathrm{N}=162,082) \\
\text { - Cannabis use disorder (CUD) }(\mathrm{N}=358,534) \\
\text { - Drinks per week }(\mathrm{N}=941,280) \\
\text { - Frequency of consuming }>6 \text { drinks }(\mathrm{N}=143,658) \\
\text { - } \text { Alcohol use disorder (AUD) }(\mathrm{N}=28,757)\end{array}$ \\
\hline $\begin{array}{c}\text { Outcomes: } \\
\text { COVID-19: }\end{array}$ \\
\hline 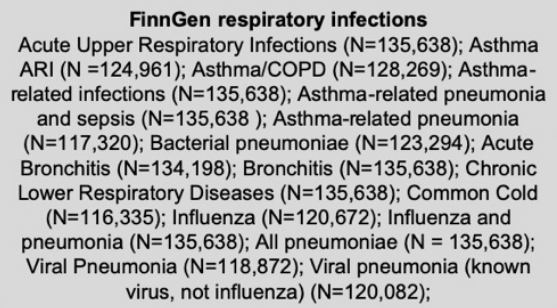 \\
\hline
\end{tabular}

SNP extraction/instrument selection

Two-sample MR

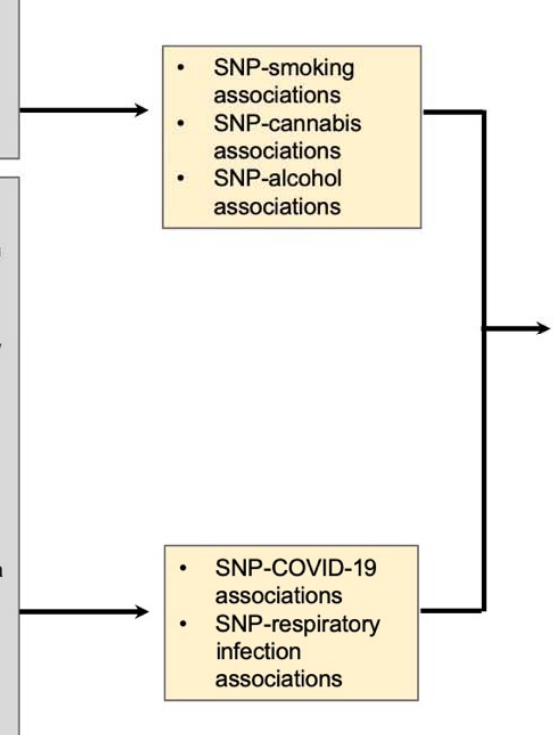

Single variable Mendelian randomization (MR):

IVW, MR Egger, Weighted Median, Weighted Mode;

Heterogeneity testing: MR Egger Intercept, MR PRESSO, Cochran Q

Multivariable MR (MVMR):

IVW, MR Egger

Heterogeneity testing: MR Egger Intercept, MR PRESSO, Cochran Q)

\section{Fig 1. Study overview.}

Abbreviations: SNP: single nucleotide polymorphism; COVID-19: coronavirus disease 2019; IVW, Inverse Variance Weighted MR; SVMR; single variable Mendelian randomization; MVMR: multivariable Mendelian randomization 
medRxiv preprint doi: https://doi.org/10.1101/2021.02.11.21251581; this version posted February 12, 2021. The copyright holder for this preprint (which was not certified by peer review) is the author/funder, who has granted medRxiv a license to display the preprint in perpetuity.

This article is a US Government work. It is not subject to copyright under 17 USC 105 and is also made available for use under a CCO license.

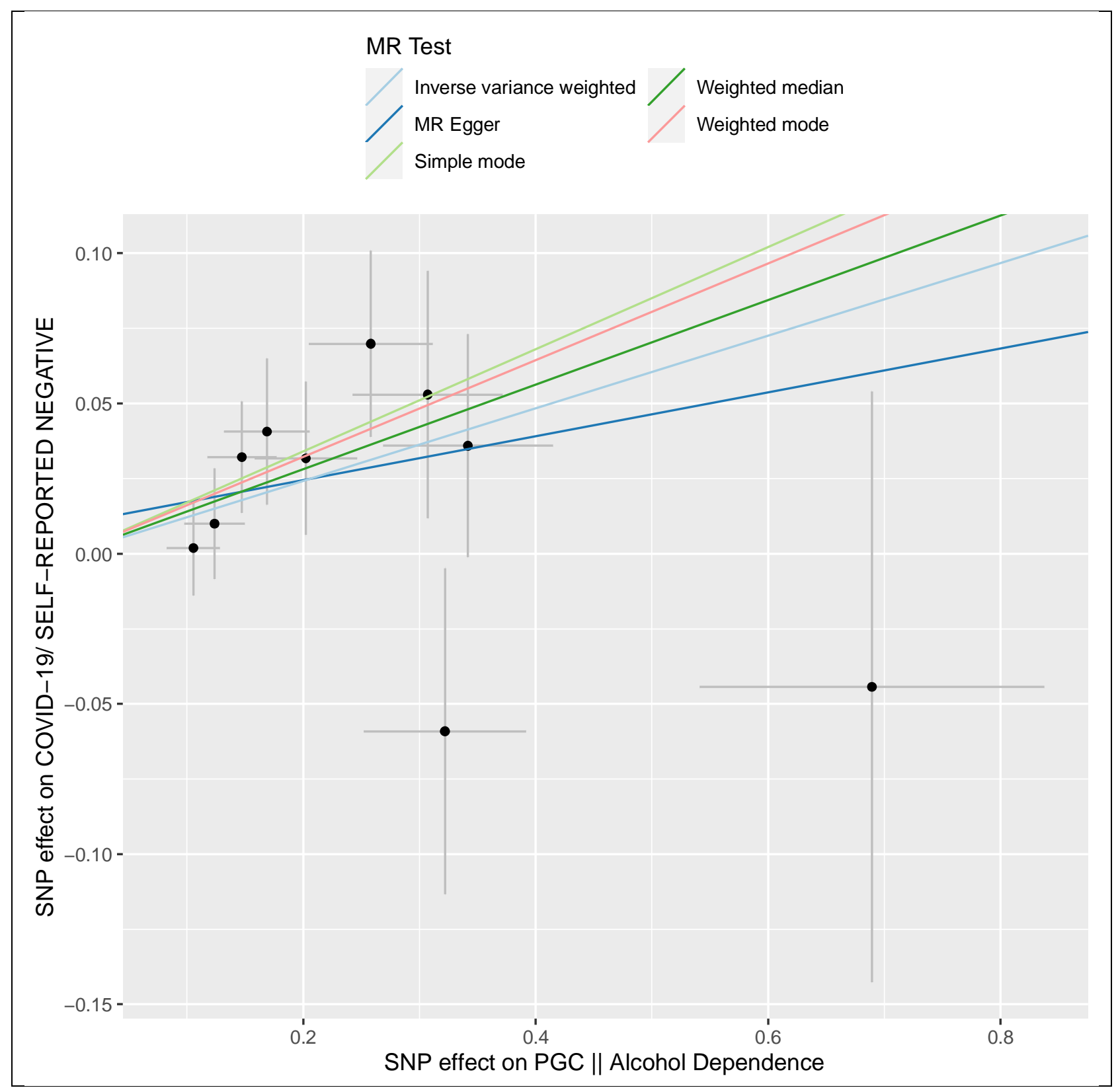


medRxiv preprint doi: https://doi.org/10.1101/2021.02.11.21251581; this version posted February 12, 2021. The copyright holder for this preprint (which was not certified by peer review) is the author/funder, who has granted medRxiv a license to display the preprint in perpetuity.

This article is a US Government work. It is not subject to copyright under 17 USC 105 and is also made available for use under a CCO license.

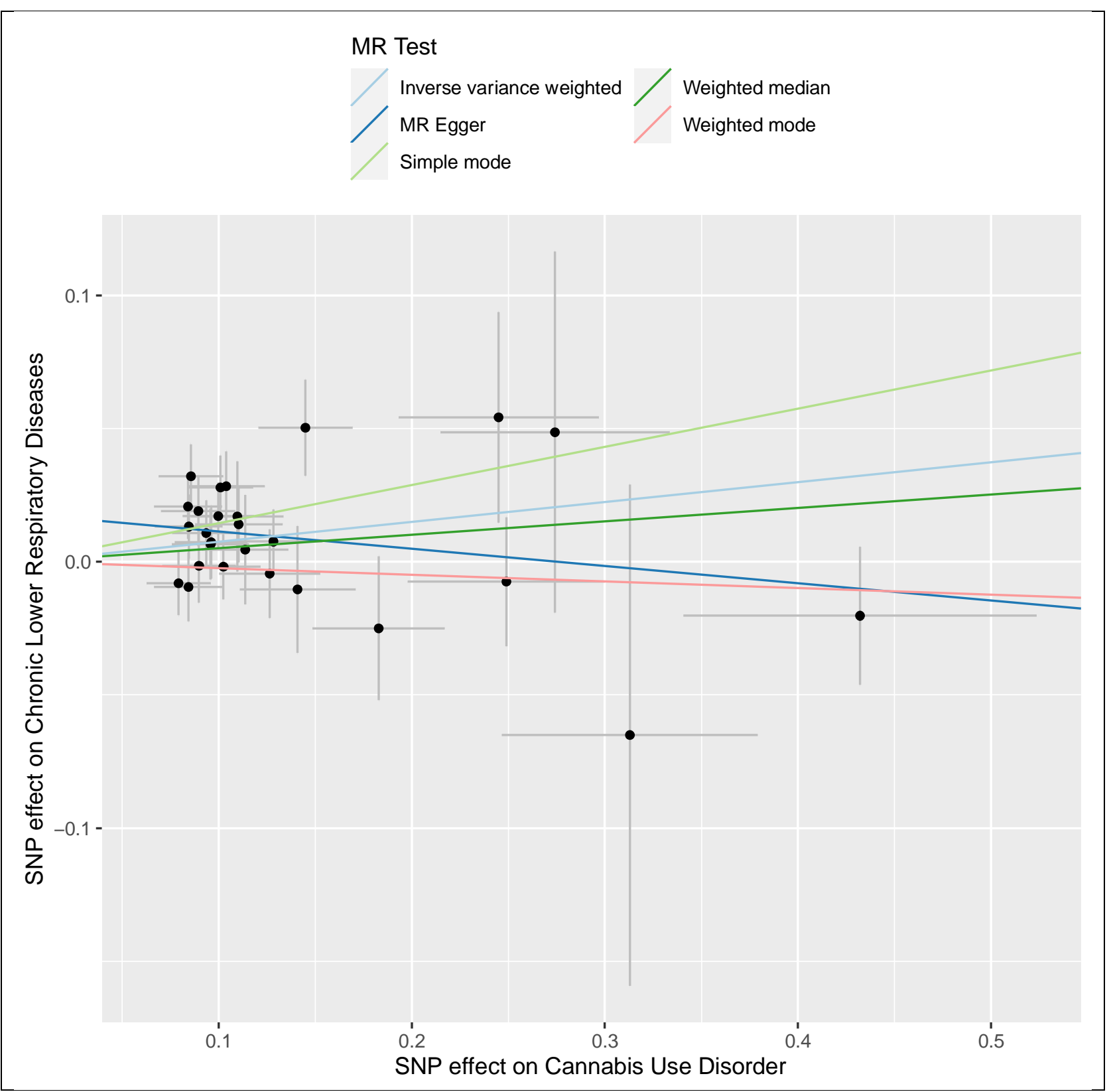

Fig 2. Scatterplot Analysis of Associations of Genetic Liability of Alcohol Dependence on COVID-19 Risk and Cannabis Use Disorder on Chronic Lower Respiratory Disease Risk

Scatterplot of single variable Mendelian randomization (SVMR) independent instrument single-nucleotide polymorphism (SNP) exposure effects versus outcome effects from 2 independent samples augmented by the standard error of these effects on the vertical and horizontal sides (for presentation, alleles are coded so that all SNP exposure effects are positive). Solid lines are the regression slopes fitted by the primary inverse variance weighted (IVW) and complementary MR methods: slopes fitted by the IVW MR method were similar in direction and magnitude to slopes fitted by complementary methods. Heterogeneity tests did not indicate residual heterogeneity, and pleiotropy robust methods did not indicate directional bias in these estimates (Tables $\mathbf{7}$ and $\mathbf{8}$ in the Supplement). 
Table 1. Single Variable MR Results of the Genetic Liability of Alcohol, Cannabis and Lifetime Smoking Exposures on COVID-19 Outcomes

\begin{tabular}{|c|c|c|c|c|c|c|}
\hline Outcome & Exposure & N SNPs & Odds Ratio & $\begin{array}{l}\text { CI Lower } \\
\text { Bound }\end{array}$ & $\begin{array}{l}\text { CI Upper } \\
\text { Bound }\end{array}$ & P-value \\
\hline \multirow[t]{5}{*}{ Hospitalized v not hospitalized } & Lifetime smoking & 91 & 1.710 & 0.689 & 4.240 & 0.247 \\
\hline & Cannabis use & 26 & 1.104 & 0.888 & 1.371 & 0.373 \\
\hline & Cannabis use disorder & 38 & 0.991 & 0.744 & 1.320 & 0.949 \\
\hline & Drinks per week & 71 & 1.229 & 0.490 & 3.079 & 0.660 \\
\hline & Alcohol use disorder & 10 & 0.897 & 0.700 & 1.151 & 0.393 \\
\hline \multirow[t]{5}{*}{ Hospitalized v population (European) } & Lifetime smoking & 91 & 4.039 & 2.335 & 6.985 & 5.93E-07 \\
\hline & Cannabis use & 25 & 1.079 & 0.929 & 1.252 & 0.320 \\
\hline & Cannabis use disorder & 37 & 1.032 & 0.829 & 1.285 & 0.780 \\
\hline & Drinks per week & 70 & 0.906 & 0.473 & 1.733 & 0.765 \\
\hline & Alcohol use disorder & 9 & 0.931 & 0.779 & 1.113 & 0.434 \\
\hline \multirow[t]{5}{*}{ Very severe hospitalized v not hospitalized } & Lifetime smoking & 91 & 3.097 & 1.883 & 5.092 & 8.40E-06 \\
\hline & Cannabis use & 25 & 0.937 & 0.454 & 1.933 & 0.860 \\
\hline & Cannabis use disorder & 38 & 1.010 & 0.862 & 1.183 & 0.901 \\
\hline & Drinks per week & 71 & 0.882 & 0.505 & 1.540 & 0.658 \\
\hline & Alcohol use disorder & 10 & 0.921 & 0.789 & 1.076 & 0.302 \\
\hline \multirow[t]{5}{*}{ COVID-19 v self-reported negative } & Lifetime smoking & 91 & 0.852 & 0.596 & 1.217 & 0.379 \\
\hline & Cannabis use & 25 & 1.031 & 0.957 & 1.112 & 0.420 \\
\hline & Cannabis use disorder & 38 & 0.940 & 0.822 & 1.076 & 0.370 \\
\hline & Drinks per week & 70 & 0.870 & 0.608 & 1.245 & 0.447 \\
\hline & Alcohol use disorder & 10 & 1.128 & 1.039 & 1.226 & 0.004 \\
\hline \multirow[t]{4}{*}{ COVID-19 v population (European) } & Lifetime smoking & 91 & 1.187 & 0.856 & 1.647 & 0.304 \\
\hline & Cannabis use & 25 & 1.019 & 0.945 & 1.098 & 0.627 \\
\hline & Cannabis use disorder & 38 & 0.964 & 0.843 & 1.101 & 0.588 \\
\hline & Drinks per week & 70 & 0.799 & 0.554 & 1.154 & 0.232 \\
\hline
\end{tabular}




\begin{tabular}{|c|c|c|c|c|c|c|}
\hline & Alcohol use disorder & 10 & 1.102 & 0.991 & 1.225 & 0.073 \\
\hline \multirow[t]{5}{*}{ COVID-19 v population } & Lifetime smoking & 91 & 1.144 & 0.845 & 1.550 & 0.383 \\
\hline & Cannabis use & 25 & 1.046 & 0.983 & 1.114 & 0.154 \\
\hline & Cannabis use disorder & 38 & 0.974 & 0.870 & 1.090 & 0.644 \\
\hline & Drinks per week & 71 & 0.818 & 0.579 & 1.156 & 0.254 \\
\hline & Alcohol use disorder & 10 & 1.061 & 0.972 & 1.158 & 0.188 \\
\hline \multirow[t]{5}{*}{ Predicted COVID-19 v self-reported negative } & Lifetime smoking & 91 & 0.887 & 0.476 & 1.653 & 0.705 \\
\hline & Cannabis use & 24 & 1.093 & 0.963 & 1.241 & 0.171 \\
\hline & Cannabis use disorder & 37 & 1.036 & 0.802 & 1.339 & 0.787 \\
\hline & Drinks per week & 71 & 0.664 & 0.332 & 1.327 & 0.246 \\
\hline & Alcohol use disorder & 10 & 1.126 & 0.965 & 1.314 & 0.131 \\
\hline
\end{tabular}

Abbreviations: MR, mendelian randomization; GWAS, genome wide association study; N SNPs, number of single-nucleotide polymorphism (genetic instruments); OR, odds ratio; CI, confidence interval.

a Results from two sample SVMR inverse-variance weighted MR analysis; outliers identified by MR PRESSO tool were removed; estimated associations reported as odds ratios with $95 \%$ confidence intervals. Boldface indicates conventional statistical significance $(\mathrm{P}<0.05)$.

b Genetic instruments selected from 5 GWASs, selection threshold $P<5 \times 10^{-8}$ or $P<5 \times 10^{-6}$, clumped at linkage disequilibrium (LD) $r^{2}=.001$ (10 000

kilobase pair window); N SNPs differs across outcomes depending on number of genetic instruments found in outcome GWASs.

Table 2. Single Variable MR Results of the Genetic Liability of Alcohol, Cannabis and Lifetime Smoking Exposures on FinnGen Infectious Disease Outcomes

\begin{tabular}{|c|c|c|c|c|c|c|}
\hline Outcome & Exposure & N SNPs & Odds Ratio & CI Lower Bound & $\begin{array}{l}\text { CI Upper } \\
\text { Bound }\end{array}$ & $\mathrm{P}$-value \\
\hline \multirow[t]{4}{*}{ Acute nasopharyngitis (common cold) } & Lifetime smoking & 117 & 2.330 & 1.059 & 5.129 & 0.036 \\
\hline & Cannabis use & 42 & 1.156 & 0.870 & 1.536 & 0.318 \\
\hline & Cannabis use disorder & 27 & 0.962 & 0.825 & 1.121 & 0.616 \\
\hline & Drinks per week & 89 & 1.479 & 0.677 & 3.232 & 0.327 \\
\hline
\end{tabular}




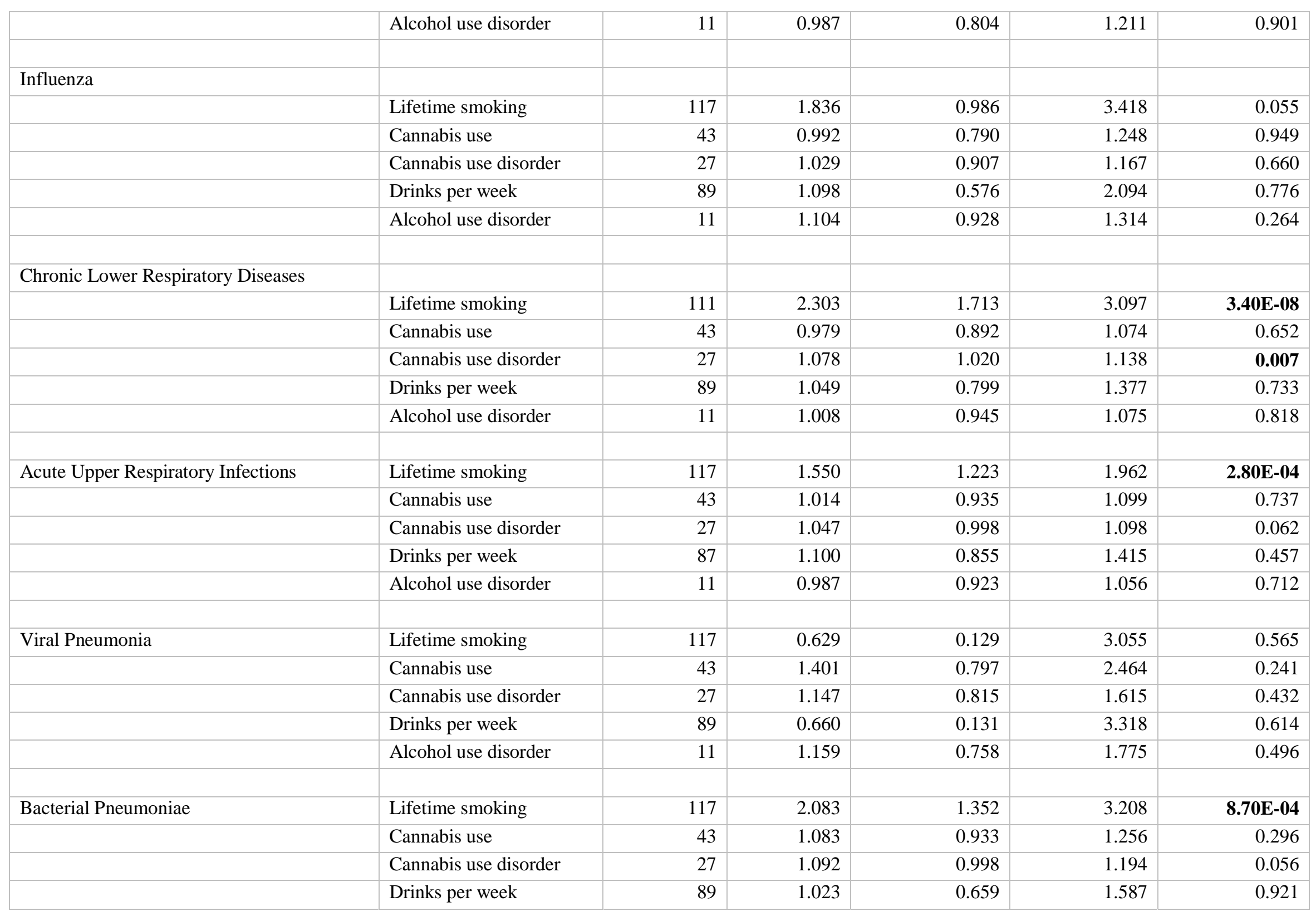




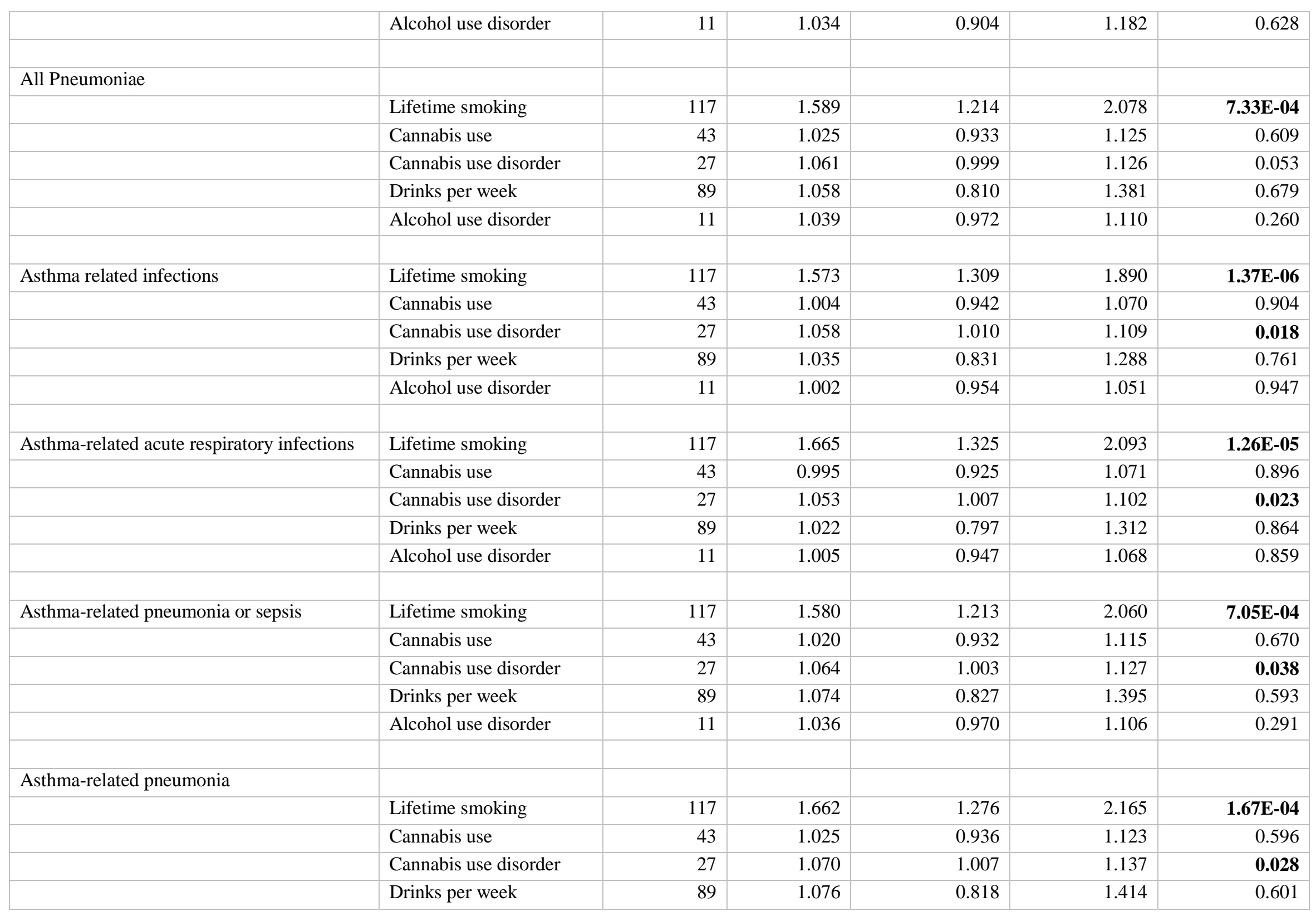




\begin{tabular}{|c|c|c|c|c|c|c|}
\hline & Alcohol use disorder & 11 & 1.033 & 0.966 & 1.104 & 0.339 \\
\hline \multirow[t]{5}{*}{ Asthma/COPD (Kela code 203) } & Lifetime smoking & 112 & 2.069 & 1.471 & 2.909 & 2.90E-05 \\
\hline & Cannabis use & 42 & 0.966 & 0.845 & 1.105 & 0.613 \\
\hline & Cannabis use disorder & 27 & 1.048 & 0.985 & 1.114 & 0.136 \\
\hline & Drinks per week & 89 & 1.059 & 0.775 & 1.447 & 0.720 \\
\hline & Alcohol use disorder & 11 & 1.014 & 0.935 & 1.099 & 0.745 \\
\hline
\end{tabular}

Abbreviations: MR, mendelian randomization; GWAS, genome wide association study; N SNPs, number of single-nucleotide polymorphism (genetic instruments); OR, odds ratio; CI, confidence interval. Boldface indicates conventional statistical significance $(\mathrm{P}<0.05)$.

a Results from two sample SVMR inverse-variance weighted MR analysis; outliers identified by MR PRESSO tool were removed; estimated associations reported as odds ratios with $95 \%$ confidence intervals.

b Genetic instruments selected from 5 GWASs, selection threshold $P<5 \times 10^{-8}$ or $P<5 \times 10^{-6}$, clumped at linkage disequilibrium (LD) $r^{2}=.001$ (10 000

kilobase pair window); N SNPs differs across outcomes depending on number of genetic instruments found in outcome GWASs. 